\title{
El Centro de Documentación y Archivo de la SGAE
}

\author{
María Luz GoNZÁLEZ PEÑA (Madrid) ${ }^{1}$
}

En este artículo se describe el Centro de Documentación y Archivo de la SGAE (Sociedad General de Autores y Editores), con domicilio en Madrid: su creación, sus fondos y su funcionamiento. Se habla del nacimiento de la Sociedad de Autores Españoles, de Ruperto Chapí y Sinesio Delgado, fundadores de la misma, del género musical de la zarzuela, de partituras y libretos, música sinfónica, teatro, fotografías, fondos personales, compositores, dramaturgos, derechos de autor, así como de nuestros proyectos pasados e inmediatos.

\section{Creación del CEDOA}

El Centro de Documentación y Archivo de la SGAE se crea el 23 de julio de 1993, por decisión del Consejo de Dirección de SGAE, presidido entonces, por Eduardo, Bautista. Pero, la historia de los fondos de SGAE es tan antigua como la entidad misma, se remonta al momento de su creación, el 16 de junio de 1899, por iniciativa del dramaturgo y periodista palentino, Sinesio Delgado y el compositor villenense Ruperto Chapí, a los que se unen otros 9 autores, para conseguir independizarse de los intermediarios, es decir, los editores y galerías lírico-dramáticas que gestionaban el negocio lírico-musical en el siglo XIX.

Desde 1899 hasta la actualidad, los archivos lírico y sinfónico han seguido manteniendo la función comercial con la que nacieron, mientras la riquísima biblioteca teatral estaba sólo al servicio de los autores. En julio de 1993, al crearse el CEDOA se unen los dos servicios archivo y biblioteca - y se pone este rico patrimonio a disposición de cualquiera que lo desee (González Peña 1999).

El patrimonio cultural de la SGAE comprende pues las obras que escribieron los primeros autores, socios y fundadores de la Sociedad de Autores Españoles (SAE), y por otra parte las obras administradas hasta este momento por las galerías dramático-musicales que funcionaron en España en el siglo XIX, a las que en 1901 la SAE compró sus fondos, constituyendo así un patrimonio músico-teatral sin parangón en España, sobre todo en lo que al teatro y la zarzuela de los siglos XIX y XX se refiere (Delgado 1999).

Estamos hablando de unas 2.000 partituras orquestales de zarzuela, más de 10.000 materiales de zarzuela, unos 30.000 libretos, sin contar las fotografías, las partituras sinfónicas, los libros de teatro y los diversos objetos que se han ido incorporando a nuestros fondos 
mediante legados o donaciones, que en la actualidad son ya cincuenta y aumentan cada año, con un claro predominio de legados de compositores, pero también de algunos dramaturgos, incluso de cantantes, actores y empresarios teatrales. La SGAE sigue gestionando los derechos de autor de todas estas obras y de las que sus socios van registrando. En la actualidad hay 117.509 socios, y más de un millón de obras.

\section{Fondos del CEDOA}

\section{Colección general}

La historia del archivo de la SGAE está unida a la creación y al desarrollo de la entidad, y la actividad creativa de los socios. El nacimiento de la Sociedad de Autores Españoles (SAE) está ligada al archivo de Ruperto Chapí, y a las obras de los autores que se iban incorporando a la entidad, enriqueciéndose, mediante la compra de los archivos de las editoriales que habían gestionado hasta ese momento el repertorio. Por lo tanto en nuestra colección tiene una presencia predominante el teatro lírico español de los siglos XIX y XX, sin olvidar la música instrumental y vocal no escénica.

Pero no sólo hablamos de música 'clásica', lírica y sinfónica, sino de música popular comercial que cubre un inmenso repertorio escrito entre 1940 y 1980. Contamos, además, con una de las bibliotecas teatrales más completas del país, y tenemos una colección bibliográfica especializada en Teatro, Música y Derechos de Autor. Otros fondos: hemerográfico, iconográfico y documental, complementan la riqueza de este patrimonio, de obligada consulta para cualquier estudioso de la música o del teatro español de los siglos XIX a XXI.

\section{Teatro lírico: partituras orquestales}

El archivo lírico de partituras originales comprende casi dos mil partituras de orquesta de las zarzuelas más conocidas. La mayor parte del teatro lírico español escrito entre 1849 y $1981^{2}$ se encuentra en este archivo, con 37 partituras autógrafas. Destacamos las de Barbieri: Chorizos y polacos, Gato por liebre, Gibraltar en 1890, Trocar los frenos y Robinson, en la que, además de la firma de Barbieri, encontramos datos de su estreno y de la acogida de la obra.

Por la significación de Chapí para la SAE y su archivo, hay que mencionar El rey que rabió, una de las pocas que tiene cubierta ilustrada, debida a Ramón Cilla, el dibujante de Madrid Cómico, semanario en el que trabajaban Ramos Carrión y Vital Aza, los libretistas de la obra, que se cuentan entre los 11 fundadores de la SAE.

Entre estas partituras, 182 proceden del Archivo de Florencio Fiscowich, 57 del de Eduardo Hidalgo, 14 de la compañía de Juan Orejón, y en número menor aparecen otros archivos y compañías teatrales. La mayoría, sin embargo, se realizaron, a partir de 1899, en el archivo y copistería de la SAE. En general se trata de copias fechadas y firmadas, en 
algunos casos, autógrafas. El catálogo de este archivo se publicó en 1994 y se encuentra en proceso de digitalización, alcanzando ya las 1800 partituras digitalizadas.

\section{Teatro lírico: materiales de orquesta}

Alrededor de diez mil zarzuelas cuentan con materiales de orquesta, más el libreto y la reducción para canto y piano empleada como parte de apuntar o dirigir. Este archivo tiene una función comercial, alquilándose dichos materiales a los teatros, auditorios y compañías líricas en cualquier lugar del mundo. La colección madrileña de materiales líricos se complementa con la de los archivos musicales en las sedes de SGAE en Valencia, con cerca de trescientas cincuenta obras líricas, en su mayoría en lengua valenciana, y de Barcelona, con tres mil setecientas obras, cuatrocientas de las cuales son sarsuelas catalanas. Entre estos materiales los hay manuscritos y litografiados. Sigue en marcha el proceso de catalogación y revisión de estos materiales, para editar posteriormente el catálogo.

Estamos en proceso de digitalización de las partituras de canto y piano, y, cualquier investigador puede acceder a estos fondos en nuestra sala de consulta.

\section{Teatro lírico: libretos}

Con los materiales orquestales de zarzuela, suele encontrase el libreto y a esto hay que añadir una inmensa colección de libretos de teatro lírico, incluyendo obras de las que no se conservan materiales o partitura. Casi siempre contamos con diferentes ediciones de un mismo título y en ocasiones ejemplares manuscritos o mecanografiados que no se editaron, y a veces únicos. Son más de treinta mil volúmenes.

El archivo musical de la SGAE en Barcelona custodia otros quince mil libretos líricos. Este fondo está catalogado, y se va digitalizando respondiendo a las peticiones de diversos usuarios desde el Teatro de la Zarzuela a compañías líricas e investigadores. Esta colección se puede consultar en el catálogo colectivo del patrimonio bibliográfico español. ${ }^{3}$

\section{Teatro declamado: libretos}

Se trata de libretos editados de teatro no musical, original o traducido. Destaca por su singularidad e importancia la colección de teatro con cerca de tres mil volúmenes. Este fondo está catalogado y se puede consultar, al igual que los libretos líricos en el Catálogo Colectivo del Patrimonio Bibliográfico Español, ya aludido.

\section{Música instrumental}

Es la única sección del archivo que sigue aumentando, semana a semana, con la música de los socios de SGAE. Consta de partituras y partes de orquesta de toda la música clásica no lírica (sinfónica, coral, de cámara, etc.) presente en nuestro archivo. El fondo histórico 
cuenta con partituras de autores como Barbieri, Bretón, Chapí, Giménez, Conrado del Campo, Julio Gómez, los autores de la Generación del 27, algunas autoras como María Rodrigo, Matilde Salvador o Elena Romero, etc. Desde el momento en que se crea la SAE, los autores traen su partitura al archivo-copistería para realizar la copia de la misma y extraer los materiales de orquesta, así pues, en el archivo histórico solemos tener la partitura manuscrita, original, incluso autógrafa en muchos casos, y los materiales de orquesta manuscritos o litografiados, como ocurre en el archivo lírico de materiales. Gran importancia presentan las obras sinfónicas escritas para la danza y el cine. En 1995 se editó el Catálogo de la parte histórica, compuesto de unas 2.000 obras, pero la catalogación es continua, ya que llegan unas 100 partituras semanales. A día de hoy hay 41.000 registros en ese archivo.

\section{Repertorio de pequeño derecho}

Es un conjunto, de unas cuarenta mil partituras, que incluyen guiones manuscritos, materiales para diversas agrupaciones instrumentales (desde bandas de rock a orquestinas) y reducciones para canto y piano manuscritas o editadas. Es clave a la hora de estudiar el repertorio de música popular española entre 1940 y 1980. Está en proceso de catalogación.

\section{Fondo iconográfico}

Nuestra colección fotográfica parte de la donación del compositor y archivero de la SGAE Ángel Andrada (1888-1949), que reunió las fotos dedicadas a él por diversos autores y compositores. Las fotografías son de prestigiosos profesionales como Compañy, Alfonso, etc.

A dicho fondo se han ido sumando, por compra o donación, más fotografías de autores e intérpretes y de montajes de obras músico-teatrales. Destacan de manera especial las colecciones de fotos donadas por los dramaturgos Eduardo Marquina, Francisco Serrano Anguita y Antonio Buero Vallejo, el compositor Pablo Luna y el matrimonio formado por Carmen Cobeña y Federico Oliver. Este fondo iconográfico se complementa con imágenes digitales de portadas o ilustraciones interiores de publicaciones o documentos de otras secciones del archivo. Hablamos de unas cinco mil imágenes, inventariadas y digitalizadas, que se han usado en varias publicaciones. Hay que destacar un manuscrito de Álvaro Retana, con fotografías de actrices, cantantes y bailarinas, parcialmente reproducido en un libro editado por la SGAE en 1996, Mujeres de la escena.

\section{Fondos especiales}

Un sinfín de documentos y objetos heterogéneos, desde efectos personales de autores o intérpretes hasta documentos variados como autógrafos, cartas, programas de mano, folletos 
con "argumento y cantables", carteles, documentación administrativa, etc., complementan los fondos de la SGAE.

Nuestro archivo se ha visto enriquecido a lo largo de las últimas décadas con adquisiciones, donaciones y legados, de instituciones o de particulares, herederos de autores o de intérpretes. Para más detalles véase página web de la SGAE.

\section{Gestión y difusión de los fondos}

Nuestra prioridad es la catalogación y digitalización de los fondos. Hace 20 años comenzamos esta labor, dando prioridad, al archivo de partituras originales, ya catalogado y casi totalmente digitalizado. Se ha digitalizado totalmente el archivo de la UME (23.000 partituras), de modo que ahora mismo, cualquier investigador puede consultar ese rico fondo en los ordenadores de la sala de consulta. La reproducción de estas partituras se hace siempre previo permiso de la editorial. Está también finalizada la digitalización de los legados de Francisco Alonso y José Serrano.

Un gran número de partes de canto y piano del archivo de materiales, se han ido digitalizando por necesidades de investigadores para tesis o trabajos de doctorado, y lo mismo estamos haciendo con los libretos.

La consulta de estos fondos se hace en sala, aunque atendemos también numerosas consultas por teléfono, correo electrónico, y en menor medida, correo postal.

Desde la creación del CEDOA en 1993, hemos recibido a cientos de investigadores en nuestra sala de consulta, que trabajan sobre música española, fundamentalmente zarzuela, además de documentalistas, musicólogos, directores de orquesta, directores escénicos y cantantes, tanto españoles como de Europa, América Latina y Estados Unidos, siendo Francia el país del que más investigadores hemos atendido, tras los españoles, naturalmente. Fruto de estas investigaciones han sido numerosas tesis, trabajos fin de master, libros...

Hemos colaborado con el Concurso Internacional de Zarzuela Ana $\mathrm{M}^{\mathrm{a}}$ Iriarte en los cuatro años que se ha mantenido activo (2010-2014) facilitando a los concursantes las partituras que se les piden para dicho concurso. Igualmente colaboramos con el concurso Operalia de Plácido Domingo, para el que facilitamos cada año numerosos fragmentos de zarzuela.

Así mismo participamos en diversos cursos y masters, en primer lugar el Curso de Propiedad Intelectual que desde la SGAE se ofrece a los funcionarios del Ministerio de Cultura, así como el curso que la SGAE ofrece cada año, en colaboración con la OMPI (Organización Mundial de la Propiedad Intelectual), sobre gestión colectiva de los derechos de autor, en la sede de la SGAE. Además, hemos establecido convenios para recibir a becarios en prácticas con la UCM (Máster en Música Española e Hispanoamericana), la UNED-Fundación Carlos de Amberes (Curso de Experto en Archivística), y la Universidad Autónoma de Madrid (Máster en Gestión de la Documentación Musical).

A lo largo de estos años, en momentos puntuales, diversos programas de radio, televisión y prensa escrita se han ocupado de nuestros fondos, lo que les ha dado una mayor difusión 
cara al público..., efemérides como el centenario de la Gran Vía, en 2010, llevaron a la prensa y la televisión a interesarse por La Gran Vía, zarzuela, y de paso por el archivo, llegando a dedicarle un espacio en Informe Semanal. También algunos legados, han despertado gran expectación en la prensa y la radio, como el de Bernardo Bonezzi y el de Jaime Salom.

Hemos cedido fondos para numerosas exposiciones a lo largo de estos años, con temas diversos como Clarín, Daniel Montorio, Ernesto Lecuona, Pérez Galdós, la jota, el paralelo barcelonés, Barbieri, etc.; fruto de un acuerdo de colaboración con el Teatro de la Zarzuela, prestamos algunos materiales para la exposición Carmen en las colecciones españolas, en el Museo Thyssen-Bornemisza y acabamos de ceder algunas partituras para la exposición que realizará el Museo Thyssen-Bornemisza con el Teatro Real alrededor de Madama Butterfly y la atracción por Japón. Madrid, 1868-1915. En el Teatro de la Zarzuela, se han organizado desde el CEDOA exposiciones sobre Marina y Chapí, coincidiendo con las representaciones de Marina, en 2013 y Curro Vargas en 2014.

Dentro de la SGAE, hemos organizado exposiciones como la de Vital Aza en 2012, centenario de su fallecimiento, que viajó a nuestra sede en Oviedo; en 2013 dedicamos una pequeña exposición sobre Tomás López Torregrosa, también en el centenario de su fallecimiento. En 2015 celebramos una exposición sobre Amadeo Vives en nuestra sede de Barcelona. En 2016 organizamos exposiciones sobre la música en Miguel de Cervantes, Miguel Ramos Carrión para la reapertura del Teatro del mismo nombre en Zamora, su localidad natal y Jacinto Benavente.

En los últimos dos años, coincidiendo con la pequeña temporada de zarzuela que la compañía Ópera Cómica celebra en el Teatro Fernán Gómez - antiguo Centro Cultural de la Villa - también realizamos exposiciones, así en 2015 recordamos a Miguel Ramos Carrión y Manuel Nieto y en 2016 a Enrique Granados y José Echegaray, coincidiendo con el centenario de la muerte de dichos autores. En 2017 hemos montado una sobre Benito Pérez Galdós, coincidiendo con la programación de Tristana y sobre las zarzuelas La Generala y La Gran Vía, en paralelo a la temporada "Zarzuela en la Villa" de la compañía Ópera Cómica de Madrid.

Desde el nacimiento de las Jornadas de Zarzuela, organizadas en Cuenca por la Fundación Jacinto e Inocencio Guerrero, colaboramos con diversas exposiciones: Los fondos del CEDOA (2013), Las entrañas de Pérez (2014), El Teatro de Arte en España (2015) La censura teatral y El sobre verde (2016).

Así mismo organizamos diversos conciertos, bien para conmemorar los centenarios de determinados autores - Vital Aza (2012), Tomás López Torregrosa (2013), Enrique Granados (2016), Jacinto Benavente (2016) - o para dar a conocer diversos legados recibidos, como el de Luis Barta (2015), o José Serrano (2016), Fernando García Morcillo, Enrique Escudé-Cofiner, Joaquín Dicenta y Ramón Asensio Mas (2017).

En esta labor de recuperación del patrimonio, hemos dado un paso más allá, en colaboración con la Fundación Jacinto e Inocencio Guerrero, al poner en escena El terrible Pérez, zarzuela de Tomás López Torregrosa, Joaquín Valverde, Enrique García Álvarez y Carlos Arniches, realizando desde la Copistería de la SGAE una edición práctica, integrando 
diversos números de otras obras de los mismos autores para lograr una producción, que con dirección escénica de Paco Mir y musical de Nacho de Paz se estrenó en el Auditorio de Cuenca el 28 de septiembre de 2014, como colofón a las II Jornadas de Zarzuela. Esta producción obtuvo el Premio Lírico Campoamor 2015 a la mejor producción escénica. En 2015 hicimos lo mismo con El sapo enamorado pantomima de Pablo Luna que se representó en función doble con El corregidor y la molinera, y que se ha representado de nuevo en noviembre de 2016 en la Universidad Carlos III de Getafe, y en 2016 hemos preparado El sobre verde, de Jacinto Guerrero. En el pasado mes de febrero, vió la luz sobre el escenario de los Teatros del Canal La malquerida, sobre el texto de Jacinto Benavente, con música de Manuel Penella, trabajada también en nuestra Copistería a partir de la partitura manuscrita del compositor y los materiales de orquesta, conservados en nuestros Archivos.

\section{Notas}

1 María Luz González Peña es directora del Centro de Documentación y Archivo de la SGAE.

2 La última obra lírica llegada al archivo fue Fuenteovejuna de Manuel Moreno Buendía, con libreto de José Luis Martín Descalzo, estrenada en el Teatro de la Zarzuela el 16 de enero de 1981.

3 Catálogo Colectivo del Patrimonio Bibliográfico Español [Libretos de Teatro Lírico y Teatro Declamado]. http://www.mcu.es/bibliotecas/MC/CCPB/index.html (consulta 15.07.2017).

\section{Bibliografía}

Álvarez Cañibano, Antonio (ed.): Imágenes para la lírica: el teatro musical español a través de la estampa (1850-1936). Madrid: Centro de Documentación Musical/ICCMU, 1995.

Álvarez Cañibano, Antonio: "Las cubiertas de ediciones de teatro musical español (1850-1936): Funcionalidad y estética”. In: Gosálvez Lara, José / Lolo, Begoña: Imprenta y edición musical en España (ss. XVIII-XX). Madrid: Universidad Autónoma, 2012, 567-590.

Casares Rodicio, Emilio: Historia gráfica de la zarzuela I. Músicas para ver. Madrid: ICCMU, 1999. Casares Rodicio, Emilio: Historia gráfica de la zarzuela II. Del canto y los cantantes. Madrid: ICCMU, 2000.

Casares Rodicio, Emilio: Historia gráfica de la zarzuela III. Los creadores. Madrid: ICCMU, 2001.

Cortizo, María Encina (ed.): Teatro Lírico, 1. Partituras. Archivo de Madrid. Madrid: SGAE, 1994.

Delgado, Sinesio: Mi teatro: cómo nació la Sociedad de Autores (estudio introductorio M. L. González Peña). Madrid: SGAE, 1999.

González Lapuente, Alberto (moderador): “Los archivos musicales” (Programa de Radio Clásica [ R.N.E ], 21-5-2011 con Paz Fernández, directora de la Biblioteca de la Fundación Juan March, Isabel Lozano, Sección de Música de la Biblioteca Nacional, Jaime de Mendoza, de la Subdirección General de Propiedad Intelectual del Ministerio de Cultura, Mónica Pérez, directora del Archivo Sonoro de Radio Nacional de España y Ma Luz González Peña, directora del CEDOA). 
González Peña, María Luz / Suárez-Pajares, Javier / Arce Bueno, Julio: Mujeres de la escena. 19001940. Madrid: SGAE, 1996.

González Peña, María Luz: “Ante el primer Centenario de la Sociedad de Autores de España”. In: Boletin de AEDOM 5 (1998), 163-167.

González Peña, María Luz: "El CEDOA: Centro de Documentación y Archivo de la Sociedad General de Autores y Editores". In: $18^{\circ}$ Congreso de la IAML. Actas. Ponencias Españolas e Hispanoamericanas. Madrid: AEDOM, 1999, 331-334.

González Peña, María Luz: “El legado de Conrado del Campo en el Archivo de la SGAE”. In: Boletín de AEDOM 7 (2000), 117-128.

González Peña, María Luz: "El Genio de Chapí y el Ingenio de Sinesio o la feliz conjunción para la liberación de los autores". In: Cuadernos de Música Iberoamericana 18 (2009), 63-120.

González Peña, María Luz: "Vital Aza Álvarez-Buylla. En el centenario de su fallecimiento". In: Cuadernos de Música Iberoamericana 24 (2012), 213-248.

González Peña, María Luz: "La copistería de la Sociedad de Autores Españoles. Una alternativa a la edición impresa”. In: Lolo, Begoña / Gosalvez, José (eds): Imprenta y edición musical en España (siglos XVII-XX). Madrid: Universidad Autónoma de Madrid/AEDOM, 2012, 551-566.

http://www.rtve.es/alacarta/audios/tertulia-archivos-musicales (consulta 15.07.2017).

Varios Autores: Música instrumental y vocal. Partituras y materiales. Archivo Sinfónico. Madrid: SGAE, 1995.

Varios Autores: Archivo histórico de la Unión Musical Española (UME). Partituras, métodos, libretos y libros. Madrid: SGAE, 2000. 